\title{
Multilayered adipose-derived regenerative cell sheets created by a novel magnetite tissue engineering method for myocardial infarction
}

Masakazu Ishii, $\mathrm{PhD}^{1}$, Rei Shibata, MD, $\mathrm{PhD}^{1}$, Yuuki Shimizu, MD, $\mathrm{PhD}{ }^{1}$, Takashi Yamamoto, MD $^{1}$, Kazuhisa Kondo, MD $^{1}$, Yoko Inoue, BS $^{1}$, Noriyuki Ouchi, MD, $\mathrm{PhD}^{2}$, Tohru Tanigawa, MD, $\mathrm{PhD}^{3}$, Noriyoshi Kanemura, $\mathrm{MD}^{1}$, Akira Ito, $\mathrm{PhD}^{4}$, Hiroyuki Honda, $\mathrm{PhD}^{5}$, Toyoaki Murohara, $\mathrm{MD}, \mathrm{PhD}^{1}$

${ }^{1}$ Department of Cardiology, Nagoya University Graduate School of Medicine

${ }^{2}$ Department of Molecular Cardiology, Nagoya University Graduate School of Medicine

${ }^{3}$ Department of Otolaryngology, Aichi Medical University

${ }^{4}$ Kyushu University, Department of Chemical Engineering Faculty of Engineering ${ }^{5}$ Department of Biotechnology, Nagoya University Graduate School of Engineering

\section{Address correspondence to:}

Toyoaki Murohara, MD, PhD or Rei Shibata, MD, PhD

Department of Molecular Cardiology

Nagoya University Graduate School of Medicine

65 Tsurumai, Showa, Nagoya 466-8550, Japan

Tel.: +81-52-744-2148 Fax: +81-52-744-2138

E-mail: murohara@med.nagoya-u.ac.jp or rshibata@med.nagoya-u.ac.jp

Acknowledgment of grant support: This study was supported by a grant (No. 26-J-Jd08) from the Japan Science and Technology Agency and a grant (No. 20249045 to T.M.) from the Ministry of Education, Culture, Sports, Science and Technology of Japan. R. Shibata was supported by a Grant-in-Aid for Young Scientists B, Banyu Life Science Foundation International, Kanae Foundation and Kowa Life Science Foundation.

\section{Conflicts of interest: None}

Keywords: stem cell, tissue engineering, myocardial infarction, adipose-derived regenerative cells, magnetic nanoparticle 


\section{Abstract}

Background: Adipose-derived regenerative cells (ADRCs) are a promising source of autologous stem cells for regeneration and repair of damaged tissue. Herein, we investigated the therapeutic potential of ADRC sheets created by a magnetite tissue engineering technology (Mag-TE) for myocardial infarction. Methods and Results: Adipose tissue was obtained from wild-type (WT) mice and ADRCs were isolated. ADRCs incubated with magnetic nanoparticle-containing liposomes (MCLs) were cultured. MCL-labeled ADRCs were mixed with diluted extracellular matrix (ECM) precursor, and a magnet was placed on the reverse side. Magnetized ADRCs formed multilayered cell sheets after a 24-h incubation. WT mice were subjected to myocardial infarction by permanent ligation of the left anterior descending artery. We then transplanted the constructed ADRC sheet or a cell-free collagen gel sheet, as a control, onto the infarcted myocardium using an Alnico magnet before skin closure. Cardiac parameters were measured by echocardiogram, and angiogenesis was determined by tissue capillary density. ADRC sheet-treated mice showed significant improvements in systolic function, infarct wall thinning, and fibrotic length after myocardial infarction. ADRC sheet implantation also promoted angiogenesis in both the infarct area and the border zone in WT mice after myocardial infarction. The angiogenic effects of ADRC sheets were attributed to an increased expression of VEGF and bFGF mRNA in ischemic hearts. Conclusions: ADRC sheets created by this Mag-TE method protect the heart against pathological cardiac remodeling. Our ADRC sheets have the potential to be a novel regenerative strategy for ischemic heart disease. 


\section{Introduction}

Cardiovascular diseases, such as myocardial infarction (MI), are some of the leading causes of death worldwide [1]. Despite current percutaneous coronary intervention and pharmacological therapies, which have been shown to limit infarct size and preserve cardiac function, MI usually causes irreversible damage to heart tissues, such that mortality and morbidity remain high [2, 3]. Therefore, it is reasonable to develop effective adjunctive therapies for patients with MI.

In recent years, stem cell therapy has been anticipated as a new strategy for regenerative medicine. Zuk and co-workers demonstrated that adipose tissues contain mesenchymal stem cells (MSCs) termed adipose-derived regenerative cells (ADRCs) that have the ability to regenerate various tissues [4]. We have recently shown that implantation of ADRCs augments revascularization in response to ischemia [5]. Implantation of ADRCs has also been shown to promote lymphangiogenesis in a mouse model of lymphedema [6]. Recent studies have reported improved cardiac function after administrating ADRCs to treat $\mathrm{MI}$ in various animal models [7-10]. However, traditional methods, such as direct myocardium injection, have several disadvantages, including rapid cell loss caused by leakage of the injected cell suspensions and needle-mediated direct tissue damage [11-13]. Thus, alternative cell application strategies have been explored.

We recently reported a tissue engineering (TE) strategy, termed the magnetic force-based TE (Mag-TE) system [14, 15]. Magnetite $\mathrm{Fe}_{3} \mathrm{O}_{4}$ nanoparticles were first taken up by liposomes, creating magnetic cationic 
liposomes (MCLs) with a positive surface charge. MCLs can easily contact target cells electrostatically because the cell membrane is negatively charged. Target cells are thereby magnetized by fusion with MCLs. Employing this method, we succeeded in creating MSC and iPS cell sheets, comprised of 10-15 piled-up cells, with an approximately $300 \mu \mathrm{m}$ thickness $[16,17]$. Implantation of these sheets augmented ischemia-induced angiogenesis in a mouse model of hindlimb ischemia. However, the effects of these multilayered sheets created using ADRCs on MI have not yet been clarified. Herein, we attempted to construct multilayered ADRC sheets using the Mag-TE system. Furthermore, we investigated the therapeutic impacts of $\mathrm{ADRC}$ sheets for $\mathrm{MI}$ in vivo using a mouse model. 


\section{Materials and Methods}

\section{Cell culture}

C57BL/6J 8-10-week old male mice were obtained from SLC (Nagoya, Japan), and cared for and used in accordance with the guidelines of the National Institutes of Health. ADRCs were isolated from inguinal fat pads of these mice as described previously [5]. Under general anesthesia with pentobarbital sodium (50 mg/kg i.p.), ADRCs were isolated from inguinal fat pads $(0.1-0.2 \mathrm{~g}$ ) obtained from C57BL/6J mice. Adipose tissues were minced and digested with $2 \mathrm{mg} / \mathrm{mL}$ type I collagenase (Wako, Osaka, Japan) at $37^{\circ} \mathrm{C}$ for $45 \mathrm{~min}$. After filtration through a $100 \mu \mathrm{m}$ filter (BD Falcon, Bedford, MA, USA) to remove cellular debris, the tissues were centrifuged at $1,300 \mathrm{rpm}$ for $5 \mathrm{~min}$. ADRCs were then suspended in Dulbecco's modified Eagle's medium (DMEM) supplemented with $10 \%$ fetal bovine serum (FBS), and antibiotics (100 U/mL penicillin $\mathrm{G}$, and 100 $\mu \mathrm{g} / \mathrm{mL}$ streptomycin) and cultured at $37^{\circ} \mathrm{C}, 5 \% \mathrm{CO}_{2}$. When adherent cells reached confluence, the attached ADRCs were reseeded in a similar medium at a concentration of $2.0 \times 10^{3}$ cells $/ \mathrm{cm}^{2}$. For most experiments, first and second passages of ADRCs were used.

\section{Angiogenic factor protein array}

Cell lysates from ADRCs cultured for $48 \mathrm{~h}$ under normoxic $\left(5 \% \mathrm{CO}_{2}\right.$ and $95 \%$ air $)$ and hypoxic $\left(5 \% \mathrm{O}_{2}, 5 \% \mathrm{CO}_{2}\right.$ and $\left.90 \% \mathrm{~N}_{2}\right)$ conditions were tested using a Proteome Profiler Angiogenesis Array Kit (R\&D Systems, Minneapolis, MN, USA). The samples were analyzed according to the manufacturer's instructions. Nitrocellulose membranes, spotted with 53 different angiogenesis related 
antibodies in duplicate, were incubated with each cell lysate and a cocktail of biotinylated detection antibodies. Any protein-detection antibody complex present is bound by its cognate-immobilized capture antibody on the membrane. Following a wash to remove unbound material, streptavidin-horseradish peroxidase and chemiluminescent detection reagents were added sequentially. The developed film was further scanned using a Fujifilm Luminescent Image Analyzer LAS-4000 (Fujifilm), and densitometric analysis was performed on the array image using Image $\mathrm{J}$ software (http://imagej.nih.gov/ij/).

\section{Differentiation assay}

To induce differentiation into smooth muscle cells and endothelial cells (ECs), ADRCs were cultured in HuMedia SB2 (smooth muscle cell basal medium; Clonetics, San Diego, CA, USA) supplemented with SD-2 and EBM-2 (EC basal medium; Clonetics) supplemented with EGM-2 MV. At day 14, adherent cells were stained with $\alpha$-smooth muscle actin ( $\alpha$-SMA) monoclonal antibody (mAb) (Sigma Aldrich, St. Louis, MO, USA) and anti-CD31 mAb (Becton Dickinson, Franklin Lakes, NJ, USA). After immunofluorescence staining, nuclei were stained with DAPI (Wako). To induce differentiation into adipocytes, ADRCs were cultured with adipogenic differentiation medium comprised of $0.5 \mathrm{mM}$ 3-isobutyl-1-methylxanthine, $1 \mu \mathrm{M}$ dexamethasone, $50 \mu \mathrm{M}$ indomethacin, and 10 $\mu \mathrm{g} / \mathrm{mL}$ insulin in $\alpha-M E M$. After 2 weeks of differentiation, adipocytes were identified by the existence of lipid vesicles stained with Oil red $O$.

\section{Effects of MCLs on proliferation and differentiation of ADRCs}


The toxicity of MCLs against ADRC growth was examined using a previously published method [14]. Briefly, ADRCs $\left(1 \times 10^{5}\right.$ cells $)$ were seeded into a $60 \mathrm{~mm}$ culture dish with $5 \mathrm{~mL}$ of culture medium, containing $100 \mathrm{pg} / \mathrm{cell}$ MCLs. Cell number was counted after $24 \mathrm{~h}$ and then cultured for $48 \mathrm{~h}$ by the dye-exclusion method with trypan blue. To induce smooth muscle and adipogenic differentiation of MCL labeled (+) or unlabeled (-) ADRCs, ADRCs were cultured in Lab-Tek culture slide (Nunc, Rochester, NY, USA) with the culture medium containing $100 \mathrm{pg} / \mathrm{cell}$ MCLs. After $24 \mathrm{~h}$ of incubation, the culture medium was replaced with HuMedia SB-2 supplemented with SD-2, EBM-2 supplemented with EGM-2 MV, or adipogenic induction medium. After 2 weeks of differentiation, the cells were stained with $\alpha$-SMA to detect smooth muscle differentiation, anti-CD31 to detect endothelial cells differentiation, and stained with Oil red $\mathrm{O}$ to detect adipogenic differentiation.

\section{Construction of ADRC sheets}

ADRC sheets were constructed by combining the Mag-TE and extracellular matrix (ECM)-based techniques, using our previously published method $[17,18]$. Briefly, the collagen solution was prepared by mixing type I collagen (Nitta Gelatin, Osaka, Japan), $10 \times$ Medium 199, neutralization buffer $(0.05 \mathrm{~N} \mathrm{NaOH})$, and FBS at a volume ratio of 7:1:1:1. An MCL-labeled ADRC suspension (5 $\times$ $10^{5}$ cells in $50 \mu \mathrm{L}$ ) was mixed with an ECM precursor solution composed of 85 $\mu \mathrm{L}$ collagen solution and $15 \mu \mathrm{L}$ Matrigel basement matrix (BD Biosciences, San Jose, CA, USA). The final concentration of type I collagen was adjusted to 0.5 $\mathrm{mg} / \mathrm{mL}$. Subsequently, the mixture $(150 \mu \mathrm{L})$ was placed in a well of a 24 -well 
ultra-low attachment plate, in which cloning rings (diameter, $5 \mathrm{~mm}$; height, 10 mm; ASAHI GLASS CO., LTD, Tokyo, Japan) were placed at the center of each well. Immediately thereafter, a magnet was placed underneath the wells to accumulate MCL-labeled ADRCs at the bottom of the culture. After the formation of cell layers, excess ECM precursor on top of the cell layer was carefully aspirated using a micropipette. The procedure was conducted under cold conditions. The remaining ECM within the cell layer was then hardened by incubation for $1 \mathrm{~h}$ at $37^{\circ} \mathrm{C}$. Culture medium was then added to each well.

\section{Mouse model of myocardial infarction}

We used 8-10 week old C57BL/6J male mice. MI was produced under anesthesia with sodium pentobarbital $(30 \mathrm{mg} / \mathrm{kg}$, i.p.) and the mice were ventilated with a volume-regulated respirator. This $\mathrm{MI}$ model was created by ligation of the left anterior descending artery with an 8-0 ethylon suture $(n=50)$. Some animals received a sham operation $(n=5)$. Mice were randomly divided into 2 groups: ADRC sheets transplanted $(n=25)$ and cell-free collagen gel sheet transplanted as a control $(n=25)$. ADRC sheets or collagen gel sheets were placed on the surface of the infarcted myocardium after 1 min of coronary occlusion and 15 min after transplantation, the chest was closed with a simple interrupted 5-0 ethylon suture. In some experiments, ADRCs labeled or unlabeled with MCLs $\left(5 \times 10^{5}\right.$ cells/50 $\mu$ L in PBS $)$ were transplanted into 5 sites in the ischemic heart by a needle injection ( $n=25$ for each group).

\section{Assessment of cardiac function}


To measure left ventricular (LV) wall thickness and chamber dimensions, an echocardiography was performed with an Acuson Sequioa C512 machine with a 15L8 probe (SIEMENS, Munich, Germany) [19]. After obtaining a good quality 2-dimensional image, M-mode images of the LV dimension and wall thickness were measured.

\section{Histological analysis}

For histological evaluation, ADRC sheets were washed with phosphate buffered saline, fixed in $4 \%$ paraformaldehyde, and embedded in paraffin. Thin $(5 \mu \mathrm{m})$ sections were stained with hematoxylin and eosin. At day 14 after surgery, mice were euthanized with an overdose of anesthetics and hearts were harvested, fixed in $4 \%$ paraformaldehyde, and embedded in paraffin. Sections $(5 \mu \mathrm{m})$ were cut and stained with Masson trichrome (Sigma Aldrich). The area of fibrosis was quantitatively analyzed with $\mathrm{NIH}$ Image software (National Institute of Health Service Branch, rsb.info.nih.gov/nih-image/). Five micrometer frozen sections were prepared and stained for anti-CD31 mAb to detect capillary ECs. The number of capillary ECs was counted using fluorescence microscopy $(200 \times)$. Five fields from 3 different samples, harvested from each animal, were randomly selected for the capillary density analysis.

To examine the extent of apoptosis, sections from frozen tissue samples were subjected to terminal deoxynucleotidyl transferase (TdT)-mediated in situ fluorescein-conjugated dUTP nick end-labeling (TUNEL) assay using the In situ Cell Death Detection Kit (Roche Diagnostics, Indianapolis, IN, USA). Nuclei were counterstained with DAPI. The number of apoptotic cells was counted and 
expressed as the percentage of the total number of nuclei in the sections.

To detect the in vivo differentiation of transplanted ADRC sheets within the host tissues, frozen serial sections were stained with anti-CD140b mAb for pericytes, anti-CD31 mAb for endothelial differentiation, and cardiac troponin $\mathrm{T}$ for myocardial differentiation.

\section{Real Time RT-PCR analysis}

Total RNA was isolated using Trizol (Invitrogen, Carlsbad, CA, USA) from ischemic hearts at day 7 and 14. Reverse transcription was performed with $1 \mu \mathrm{g}$ of RNA, random primers, and MMLV reverse transcriptase (ReverTra Ace- $\alpha$ TOYOBO, Osaka, Japan). Quantitative real-time PCR was performed with the LightCyclerT System (Roche Diagnostics, Basel, Switzerland) and QuantiTect SYBR Green PCR kit. The Primer sequences used are: VEGF-A: sense, 5'-CAGGCTGCTGTAACGATGAA-3', and antisense, 5'-AATGCTTTCTCCGCTCTGAA-3', bFGF: sense, 5'-AGCGGCTCTACTGCAAGAAC-3', and antisense, 5'-GCCGTCCATCTTCCTTCATA-3', GAPDH: sense, 5'-ACCCAGAAGACTGTGGATGG-3', and antisense, 5'-CACATTGGGGGTAGGAACAC-3'.

\section{Statistical analysis}

The data are presented as means \pm SEM values. Comparisons between 2 groups were made using Student's $t$ test. Statistical analysis for multiple 
comparisons among the groups was performed using one-way ANOVA (Fig. 3G). Survival rates were compared using Kaplan-Meier curves and the log-rank test (Fig. 3B). Statistically significant differences were considered at $p<0.05$ 


\section{Results}

\section{Characterization of cultured ADRCs}

First, we assessed the characteristics of ADRCs magnetically labeled with MCLs. The inclusion of MCLs (100 pg/cells) in the medium did not affect the growth rate of ADRCs (Fig. 1A). Smooth muscle cells and adipocytes, but not ECs, were induced from ADRCs labeled or unlabeled with MCLs. Immunofluorescence analysis revealed that $\alpha-\mathrm{SMA}^{+}$smooth muscle cells and Oil Red $\mathrm{O}^{+}$adipocytes, but not CD31+ ECs, were selectively induced from ADRCs, regardless of the presence or absence of labeling with MCLs (Fig. 1B). Thus, the incorporation of magnetic particles within the cells did not alter their phenotypes.

We next examined the expression of angiogenic cytokines using the Proteome Profiler array under conditions of normoxia or hypoxia. Representative immunoblots are presented in Figure 1C. In culture, ADRCs labeled with MCLs expressed multiple angiogenic factors under normoxic or hypoxic conditions. Of note, hypoxia significantly increased the expression of bFGF and VEGF (Fig. 1D).

Construction of ADRC sheets by combining Mag-TE and ECM precursor embedding systems

Mouse ADRC sheets were constructed using the Mag-TE and ECM precursor embedding systems in combination. Figure 2A presents a macroscopic en face view of ADRC sheet constructed on an ultra-low-attachment culture plate. The ADRC sheet was brown, the color of magnetite $\mathrm{Fe}_{3} \mathrm{O}_{4}$ nanoparticles. The sheet was nearly circular with a diameter of $5 \mathrm{~mm}$. Hematoxylin and eosin staining 
showed that ADRC sheets had a "reticular pattern structure" comprised of pile-ups of 10-15 layered cells with an approximately $300 \mu \mathrm{m}$ thickness (Fig. 2B). Also, virtually no TUNEL positive-apoptotic cells were observed after the initiation of the sheet construction (Fig. 2C). Thus, we succeeded in creating ADRC sheets by combining the Mag-TE and ECM precursor embedding systems.

Transplantation of ADRC sheets improved cardiac remodeling after myocardial infarction

We examined the effects of in vivo implantation of an ADRC sheet on cardiac remodeling after MI. A neodymium magnet under the culture plate was removed. Then, an Alnico magnet covered with a hydrophilic PVDF film was positioned on the surface of the culture medium. A sheet was placed on the surface of the infarcted myocardium. After $15 \mathrm{~min}$, sheets were tightly attached to the heart surface (Fig. 3A). The skin was closed with a simple interrupted 5-0 suture after the cell sheet placement.

Body weights (BW) did not differ between the ADRC sheet and control (Collagen gel) groups at 4 weeks after $\mathrm{Ml}$ or sham operation. No significant difference in heart rate was observed among the experimental groups. Systolic blood pressure was significantly decreased in both the ADRC sheet and the control group 4 weeks after Ml compared to the sham-operated mice, but the difference between the ADRC sheet and control groups did not reach statistical significance (data not shown). All sham-operation mice survived and appeared healthy during the follow-up period. Mortality after MI was significantly lower in 
the ADRC sheet group than in the control group (Fig. 3B).

At 28 days after surgery, cardiac function was assessed by echocardiography. Figure $3 \mathrm{C}$ shows representative M-mode echocardiograms for the ADRC sheet and control groups at 28 days after sham operation or MI. Echocardiographic measurements revealed that the decrease in LVFS and LVEF following MI were improved by ADRC sheet implantation (Fig. 3D and E). No difference in LVFS or LVEF was detected between the sham-operated, ADRC sheet, and control groups. Furthermore, we assessed the effect of ADRC transplantation by a needle injection on cardiac remodeling after MI to compare it to that of transplanted ADRC sheet. ADRCs labeled or unlabeled with MCLs $(5 \times$ $10^{5}$ cells $/ 50 \mu \mathrm{L}$ in PBS) were transplanted into 5 sites in the ischemic heart by a needle injection. Implantation of ADRC by a needle injection did not affect mortality and LV systolic function after MI (Fig. 3B-E).

Hearts were also processed for histological analyses. Masson trichrome staining revealed that interstitial fibrosis in the LV myocardium was increased following Ml (Fig. 3F and G). This increase in the extent of cardiac fibrosis was significantly inhibited by ADRC sheet implantation (Fig. 3F and G). Implantation of ADRC labeled or unlabeled with MCLs by a needle injection had no effect on the LV interstitial fibrosis after Ml (Fig. 3F and G). There was no significant difference in LV interstitial fibrosis after sham operation between the ADRC sheet and control groups. Collectively, these data show that ADRC transplantation can reduce MI-induced LV remodeling.

\section{Modulation of myocardial capillary density and apoptosis with ADRC sheet}




\section{transplantation}

Capillary status was evaluated by histological analysis of CD31-positive cells in both the peri-infarct and remote areas of the myocardium (Fig. 4A). Capillary density in the peri-infarct area was significantly increased in the ADRC sheet group compared to the control group at 2 weeks after Ml, whereas there was no significant difference in the capillary density in the remote area after MI between the ADRC sheet and control groups. There was no significant difference in the capillary density at 2 weeks after sham-operation in the remote area after MI between the ADRC sheet and control groups. No difference was detected in the capillary density at 2 weeks after sham-operation between the sham-operated ADRC sheet and control groups. To investigate the extent of apoptosis, TUNEL staining was performed on histological sections from the peri-infarct and remote areas in the different experimental groups (Fig. 4B). Quantitative analysis showed a significantly lower proportion of TUNEL-positive cells in the peri-infarct area of the heart in the ADRC sheet group compared to that of the control group. There was no significant difference in the frequency of apoptotic cells in the remote area after MI between the ADRC sheet and control groups. Few or no TUNEL-positive cells were detectable in the heart of sham-operated mice.

\section{ADRC sheet transplantation increased VEGF and bFGF expression in ischemic myocardium}

Because angiogenic cytokines play an important role in the regulation of coronary angiogenesis, we assessed cardiac expressions of VEGF and bFGF at day 7 and 14 after MI by real-time PCR. Coronary ligation significantly increased 
cardiac VEGF and bFGF mRNA expression in the control group at day 7, but the increase in VEGF and bFGF in the heart following MI were significantly greater in the ADRC sheet group (Fig. 5A and B). There was no significant difference in cardiac expression of VEGF and bFGF at day 14 after sham-operation or MI between the ADRC sheet and control groups.

\section{Location of ADRC sheet after transplantation}

We examined the cell types that implanted ADRCs differentiated into. A large number of newly-formed capillary and mature blood vessels invaded the ADRC sheet at 14 days after transplantation. Immunofluorescence staining revealed that some of the implanted ADRCs resided near vascular structures and capillaries stained with CD31 (Fig. 6A). These cells were positive for CD 140b, a pericyte marker (Fig. 6A). In addition, implanted ADRCs did not co-stain positively for Troponin T. Thus, implanted ADRCs might contribute, at least to a limited extent, to vascular formation as pericytes in the chronic phase (Fig. 6B). 


\section{Discussion}

In the present study, we successfully created multi-layered ADRC sheets by combining a TE modality, termed the Mag-TE system, and the ECM precursor embedding system. This sheet was engrafted into ischemic hearts. Transplantation of ADRC sheets protected against adverse cardiac remodeling following MI.

We previously reported that transplantation of MCL-labeled cell sheets promoted angiogenesis more effectively than conventional direct-injection of cell suspensions using MSCs and iPS cells [16, 17]. It takes only $24 \mathrm{~h}$ to create these cell sheets. Furthermore, we can construct a variety of cell sheets, such as cardiomyocytes, keratinocytes, and hepatocytes, employing this Mag-TE technology $[14,15,20,21]$. Recently, we succeeded in creating stem cell sheets using MSCs or iPS cells. The transplanted MSC and iPS cell sheets were engrafted into skeletal muscles of mice and stimulated angiogenesis in response to limb ischemia $[16,17]$. In the present study, ADRC sheets, created using the same method, were constructed and engrafted into heart tissue. Collectively, our methodology, the Mag-TE and ECM embedding system, has been shown to be extremely useful and convenient, suggesting that these methods provide a modality applicable to various fields of regenerative medicine.

Agents that promote angiogenesis have been shown to be beneficial for cardiac remodeling after myocardial ischemia. In fact, a number of clinical trials have supported the efficacy of therapeutic angiogenesis by cell transplantation for MI [22-25]. Previously, implantation of ADRCs was shown to promote angiogenesis in response to ischemia $[5,26]$. In the present study, implantation 
of $A D R C$ sheets resulted in improved cardiac function that was associated with an increase in myocardial capillaries.

One of the major mechanisms underlying improved cardiac function might be the release of angiogenic cytokines from ADRC sheets. ADRCs not only differentiate into mesenchymal tissues, but can also secrete multiple angiogenic growth factors, such as VEGF and bFGF $[26,27]$. Implantation of monolayer adipose-derived MSC sheets reportedly repaired scarred myocardium after $\mathrm{Ml}$ through paracrine effects triggering angiogenesis [28]. We also found that implantation of ADRCs induced angiogenesis not via direct differentiation into ECs, but rather by releasing cytokines in a mouse model of hind limb ischemia [5]. We and other groups have shown that ADRCs differentiated into pericytes but not ECs in vitro and in vivo $[8,29]$. Consistent with these observations, our present data indicate that implanted ADRCs contribute to vascular formation as pericytes, but not as ECs or cardiac myocytes. ADRCs labeled with MCLs highly expressed VEGF and bFGF under hypoxic conditions. In addition, implantation of our ADRC sheets increased VEGF and bFGF mRNA levels in ischemic hearts, although these factors could not be assessed at the protein level. The reason why the differentiation from ADRC to endothelial cells did not occur during the observation period remains unknown. Collectively, the ability of ADRC sheets to stimulate the release of angiogenic growth factors may contribute to the maintenance of myocardial capillary density in response to myocardial ischemia, resulting in the preservation of cardiac function. Further studies may be required to understand the precise mechanisms underlying the secretion of angiogenic cytokines by 
ADRC therapy and to test the dose-response relationship for ADRC sheets in our animal models.

Finally, ADRC sheets were placed on the surface of the infarcted myocardium after 1 min of coronary occlusion in the present study. Timing of sheet implantation after coronary occlusion could be related to a decrease of ischemic damage or a decrease of adverse remodeling. Thus, additional experimental studies will be required to assess the cardiac remodeling following ADRC sheet implantation at various time points, in animal models.

In conclusion, ADRC sheets created by this Mag-TE method protect against adverse cardiac remodeling following MI. The favorable effects of ADRC sheets are associated with maintenance of capillary density via the angiogenic paracrine actions of cytokines. Our ADRC sheets may become a novel regenerative medicine strategy for ischemic heart disease in the future. 


\section{Figure Legends}

Figure 1: Characterization of cultured ADRCs magnetically labeled with MCLs (A) Inclusion of MCLs did not affect the growth of ADRCs. Open circles, MCL-unlabeled ADRCs; solid circles, MCL-labeled ADRCs (100 pg/cells). (B) In vitro differentiation assay. Cultured ADRCs labeled or unlabeled with MCLs were induced to differentiate into smooth muscle cells, ECs, and adipocytes. Inclusion of magnetic particles within ADRCs did not alter smooth muscle cell or adipocyte differentiation potential. EC differentiation was not confirmed by immunostaining with anti-CD31 antibody. Smooth muscle cell differentiation was confirmed by staining with anti-a-SMA antibody (green), counterstained with DAPI (blue). Adipogenic differentiated ADRC stained with Oil Red O. Scale bar: $50 \mu \mathrm{m}$. The expression of angiogenic cytokines in ADRCs cultured under normoxic and hypoxic conditions. Representative immunoblots (C) and quantitative analysis of relative changes in various angiogenic factors (D).

Figure 2: Construction of ADRC sheets by combining Mag-TE and ECM precursor embedding systems

(A) Bright-field photographs of the ADRC sheets constructed on an ultra-low-attachment plate using the Mag-TE and ECM embedding system. (B) Bright field microscopic photograph of HE-stained cross sections of ADRC sheets. (C) TUNEL positive-apoptotic cells were virtually absent at $24 \mathrm{~h}$ after sheet construction.

Figure 3: 
(A) ADRC sheets were tightly attached to the heart surface at 15 min after transplantation. (B) Kaplan-Meier survival curves after 4 weeks follow-up. Mice were divided into 6 groups as follows: The sham-collagen gel group received the cell-free collagen gel sheet placed on the surface of the myocardium after sham-operation. The sham-ADRC sheet group $\left(5 \times 10^{5}\right.$ cells/sheet $)$ received the ADRC sheet placed on the surface of the myocardium after sham-operation. The collagen gel group received the cell-free collagen gel sheet placed on the surface of the infarcted myocardium after MI. The ADRC sheet group $\left(5 \times 10^{5}\right.$ cells/sheet) received the ADRC sheet placed on the surface of the infarcted myocardium after MI. The ADRC (MCL-) group $\left(5 \times 10^{5}\right.$ cells $/$ mice) received the ADRCs unlabeled with MCLs by a needle injection after MI. The ADRC (MCL+) group $\left(5 \times 10^{5}\right.$ cells/mice) received the ADRCs labeled with MCLs by a needle injection after MI ( $\mathrm{n}=25$ for each group). (C-E) Analysis of cardiac function by echocardiography 28 days after operation. (C) Representative M-mode echocardiogram for the sham-collagen gel, sham-ADRC sheet, collagen gel, ADRC sheet, ADRC (MCL-), and ADRC (MCL+) groups. (D and E) Quantitative analysis of left ventricular fractional shortening (LVFS) and left ventricular ejection fraction (LVEF). (F) Cardiac fibrosis area was visualized by Masson trichrome staining. (G) Quantitative analysis of cardiac fibrosis area $(n=5$ for each group). Scale bar: $1 \mathrm{~mm}$.

Figure 4: Quantitative analysis of capillary density and apoptotic cells in ischemic hearts

(A) Microscopic photographs of capillary density in both the peri-infarct areas 
and the remote areas at day 14 after surgery. Capillaries were immunostained with anti-CD31 antibody. (B) TUNEL staining images of ischemic hearts at 14 days after transplantation. (Arrows: TUNEL-positive cells, Scale bar: $50 \mu \mathrm{m}$ ).

Figure 5: Angiogenic cytokine expressions in ischemic hearts at day 7 and 14 after surgery The mRNA expression of VEGF (A) and bFGF (B) was determined by Real-Time RT-PCR in the collagen gel and ADRC sheet groups ( $n=5$ for each group).

Figure 6: In vivo differentiation of grafted ADRC sheets within host ischemic hearts

(A) A fraction of MCL-labeled ADRCs appeared to be incorporated into perivascular regions (arrows). Red: CD31; Green: CD140b; Blue: DAPI. (B) In contrast, no transplanted ADRCs were confirmed to have differentiated into cardiomyocytes. Red: Troponin T; Blue: DAPI. Scale bar: $50 \mu \mathrm{m}$. 


\section{References}

[1] Eisenberg MS, Mengert TJ. Cardiac resuscitation. N Engl J Med. $2001 ; 344: 1304-13$.

[2] Yu LH, Kim MH, Park TH, Cha KS, Kim YD, Quan ML, et al. Improvement of cardiac function and remodeling by transplanting adipose tissue-derived stromal cells into a mouse model of acute myocardial infarction. Int $\mathrm{J}$ Cardiol. 2010;139:166-72.

[3] Jeevanantham V, Butler M, Saad A, Abdel-Latif A, Zuba-Surma EK, Dawn B. Adult bone marrow cell therapy improves survival and induces long-term improvement in cardiac parameters: a systematic review and meta-analysis. Circulation. 2012;126:551-68.

[4] Zuk PA, Zhu M, Mizuno H, Huang J, Futrell JW, Katz AJ, et al. Multilineage cells from human adipose tissue: implications for cell-based therapies. Tissue Eng. 2001;7:211-28.

[5] Kondo K, Shintani S, Shibata R, Murakami H, Murakami R, Imaizumi M, et al. Implantation of adipose-derived regenerative cells enhances ischemia-induced angiogenesis. Arterioscler Thromb Vasc Biol. 2009;29:61-6.

[6] Shimizu Y, Shibata R, Shintani S, Ishii M, Murohara T. Therapeutic lymphangiogenesis with implantation of adipose-derived regenerative cells. $\mathrm{J}$ Am Heart Assoc.1:e000877.

[7] li M, Horii M, Yokoyama A, Shoji T, Mifune Y, Kawamoto A, et al. Synergistic effect of adipose-derived stem cell therapy and bone marrow progenitor recruitment in ischemic heart. Lab Invest.91:539-52.

[8] Cai L, Johnstone BH, Cook TG, Tan J, Fishbein MC, Chen PS, et al. IFATS 
collection: Human adipose tissue-derived stem cells induce angiogenesis and nerve sprouting following myocardial infarction, in conjunction with potent preservation of cardiac function. Stem Cells. 2009;27:230-7.

[9] Bai X, Yan Y, Song YH, Seidensticker M, Rabinovich B, Metzele R, et al. Both cultured and freshly isolated adipose tissue-derived stem cells enhance cardiac function after acute myocardial infarction. Eur Heart J.31:489-501.

[10] Schenke-Layland K, Strem BM, Jordan MC, Deemedio MT, Hedrick MH, Roos KP, et al. Adipose tissue-derived cells improve cardiac function following myocardial infarction. J Surg Res. 2009;153:217-23.

[11] Tang YL, Tang Y, Zhang YC, Qian K, Shen L, Phillips MI. Improved graft mesenchymal stem cell survival in ischemic heart with a hypoxia-regulated heme oxygenase-1 vector. J Am Coll Cardiol. 2005;46:1339-50.

[12] Zhang M, Methot D, Poppa V, Fujio Y, Walsh K, Murry CE. Cardiomyocyte grafting for cardiac repair: graft cell death and anti-death strategies. J Mol Cell Cardiol. 2001;33:907-21.

[13] Pittenger MF, Martin BJ. Mesenchymal stem cells and their potential as cardiac therapeutics. Circ Res. 2004;95:9-20.

[14] Ito $A$, Hayashida $M$, Honda $H$, Hata $K$, Kagami $H$, Ueda $M$, et al. Construction and harvest of multilayered keratinocyte sheets using magnetite nanoparticles and magnetic force. Tissue Eng. 2004;10:873-80.

[15] Ito A, Takizawa $\mathrm{Y}$, Honda H, Hata K, Kagami H, Ueda M, et al. Tissue engineering using magnetite nanoparticles and magnetic force: heterotypic layers of cocultured hepatocytes and endothelial cells. Tissue Eng. 2004;10:833-40. 
[16] Ishii M, Shibata R, Numaguchi Y, Kito T, Suzuki H, Shimizu K, et al. Enhanced angiogenesis by transplantation of mesenchymal stem cell sheet created by a novel magnetic tissue engineering method. Arterioscler Thromb Vasc Biol.31:2210-5.

[17] Kito T, Shibata R, Ishii M, Suzuki H, Himeno T, Kataoka Y, et al. iPS cell sheets created by a novel magnetite tissue engineering method for reparative angiogenesis. Sci Rep.3:1418.

[18] Akiyama H, Ito A, Sato M, Kawabe Y, Kamihira M. Construction of cardiac tissue rings using a magnetic tissue fabrication technique. Int $\mathrm{J}$ Mol Sci.11:2910-20.

[19] Ogura Y, Ouchi N, Ohashi K, Shibata R, Kataoka Y, Kambara T, et al. Therapeutic impact of follistatin-like 1 on myocardial ischemic injury in preclinical models. Circulation.126:1728-38.

[20] Ito A, Hibino E, Kobayashi C, Terasaki H, Kagami H, Ueda M, et al. Construction and delivery of tissue-engineered human retinal pigment epithelial cell sheets, using magnetite nanoparticles and magnetic force. Tissue Eng. $2005 ; 11: 489-96$.

[21] Shimizu K, Ito A, Lee JK, Yoshida T, Miwa K, Ishiguro H, et al. Construction of multi-layered cardiomyocyte sheets using magnetite nanoparticles and magnetic force. Biotechnol Bioeng. 2007;96:803-9.

[22] Strauer BE, Steinhoff G. 10 years of intracoronary and intramyocardial bone marrow stem cell therapy of the heart: from the methodological origin to clinical practice. J Am Coll Cardiol.58:1095-104.

[23] Janssens S, Dubois C, Bogaert J, Theunissen K, Deroose C, Desmet W, et 
al. Autologous bone marrow-derived stem-cell transfer in patients with ST-segment elevation myocardial infarction: double-blind, randomised controlled trial. Lancet. 2006;367:113-21.

[24] Schachinger V, Erbs S, Elsasser A, Haberbosch W, Hambrecht R, Holschermann $\mathrm{H}$, et al. Improved clinical outcome after intracoronary administration of bone-marrow-derived progenitor cells in acute myocardial infarction: final 1-year results of the REPAIR-AMI trial. Eur Heart J. 2006;27:2775-83.

[25] Meyer GP, Wollert KC, Lotz J, Steffens J, Lippolt P, Fichtner S, et al. Intracoronary bone marrow cell transfer after myocardial infarction: eighteen months' follow-up data from the randomized, controlled BOOST (BOne marrOw transfer to enhance ST-elevation infarct regeneration) trial. Circulation. 2006;113:1287-94.

[26] Nakagami H, Maeda K, Morishita R, Iguchi S, Nishikawa T, Takami Y, et al. Novel autologous cell therapy in ischemic limb disease through growth factor secretion by cultured adipose tissue-derived stromal cells. Arterioscler Thromb Vasc Biol. 2005;25:2542-7.

[27] Rehman J, Traktuev D, Li J, Merfeld-Clauss S, Temm-Grove CJ, Bovenkerk JE, et al. Secretion of angiogenic and antiapoptotic factors by human adipose stromal cells. Circulation. 2004;109:1292-8.

[28] Miyahara Y, Nagaya N, Kataoka M, Yanagawa B, Tanaka K, Hao H, et al. Monolayered mesenchymal stem cells repair scarred myocardium after myocardial infarction. Nat Med. 2006;12:459-65.

[29] Rigol M, Solanes N, Farre J, Roura S, Roque M, Berruezo A, et al. Effects of 
adipose tissue-derived stem cell therapy after myocardial infarction: impact of the route of administration. J Card Fail.16:357-66. 
A

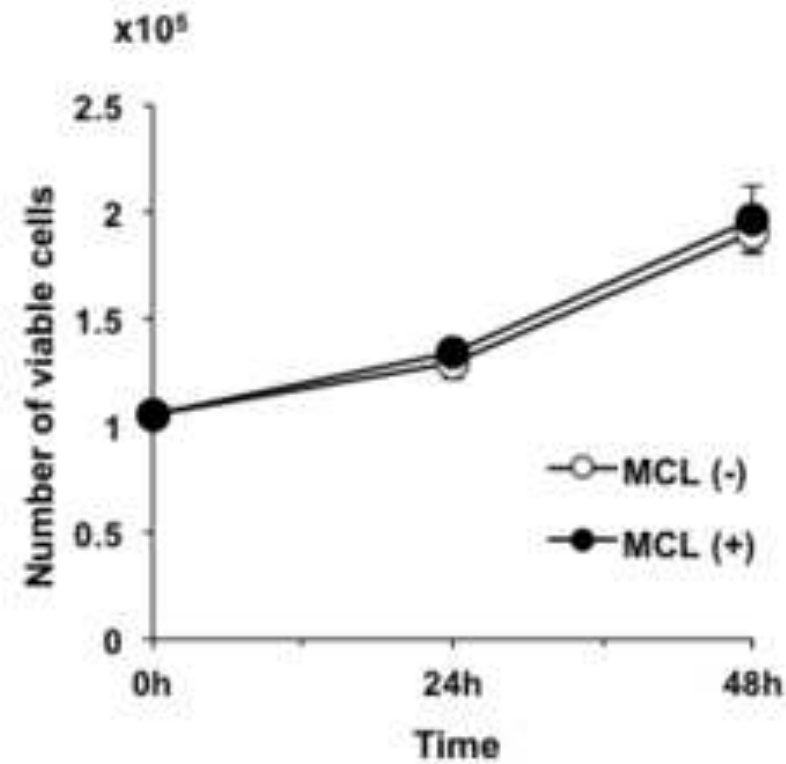

C

Normoxia

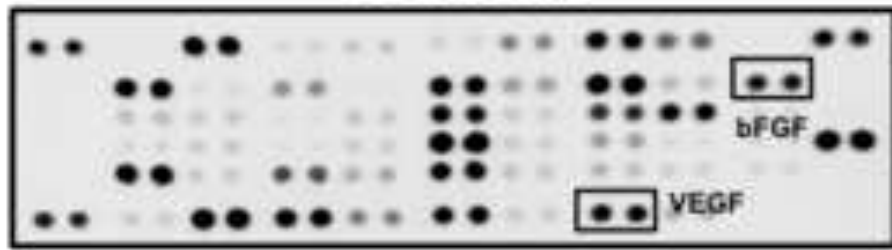

D

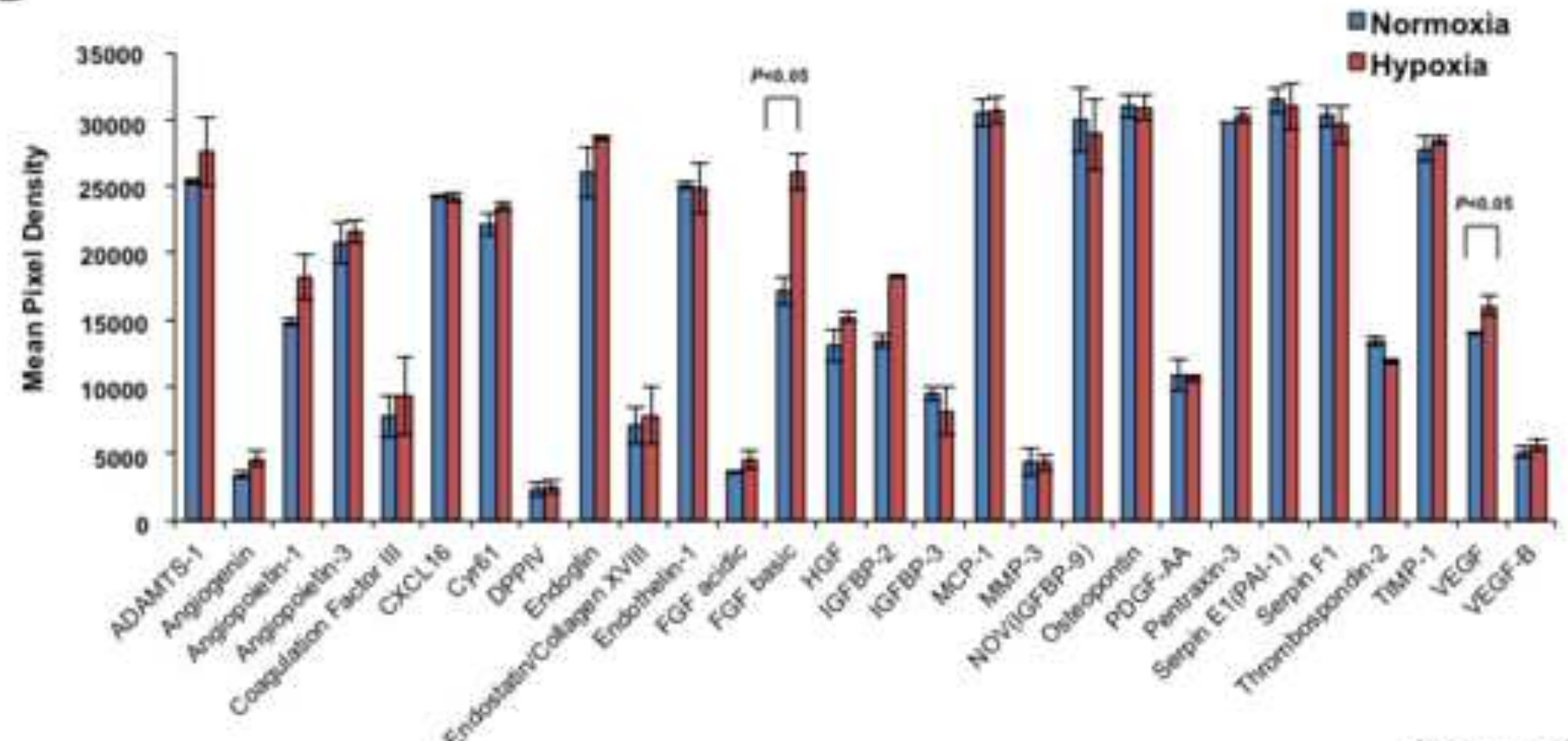

Figure 1 
A

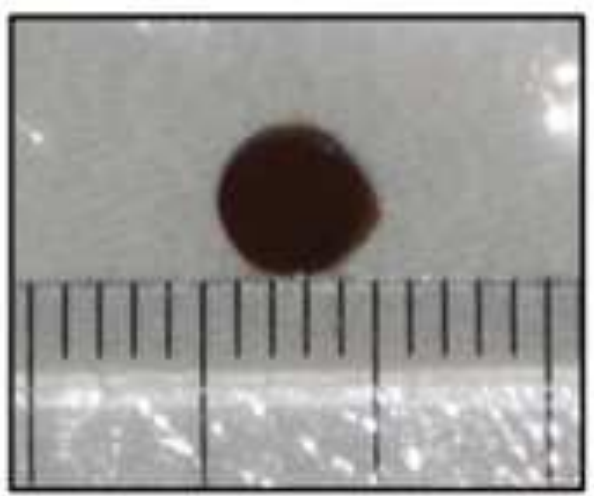

B

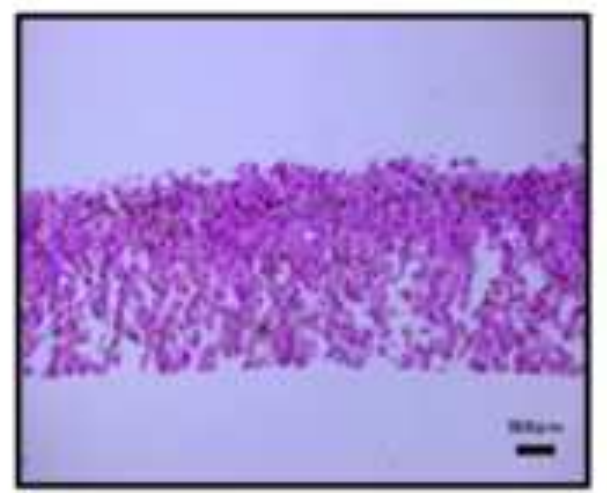

C

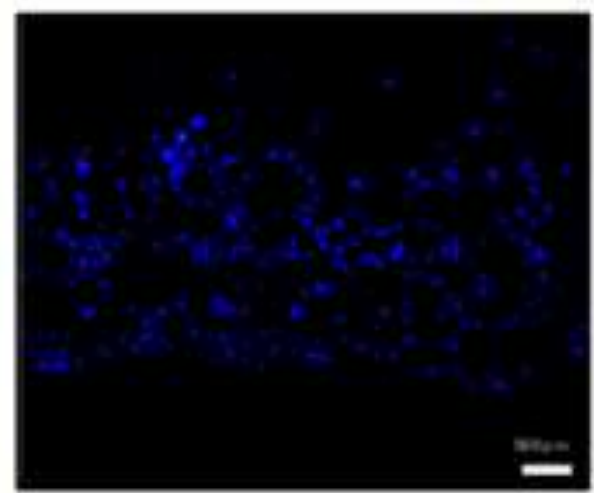

Bar: $50 \mu \mathrm{m}$

Figure 2 
A

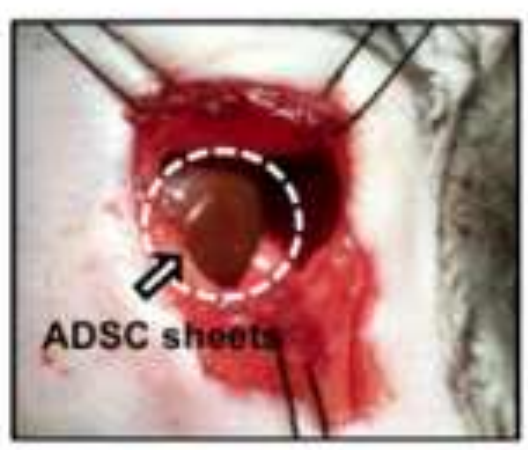

B

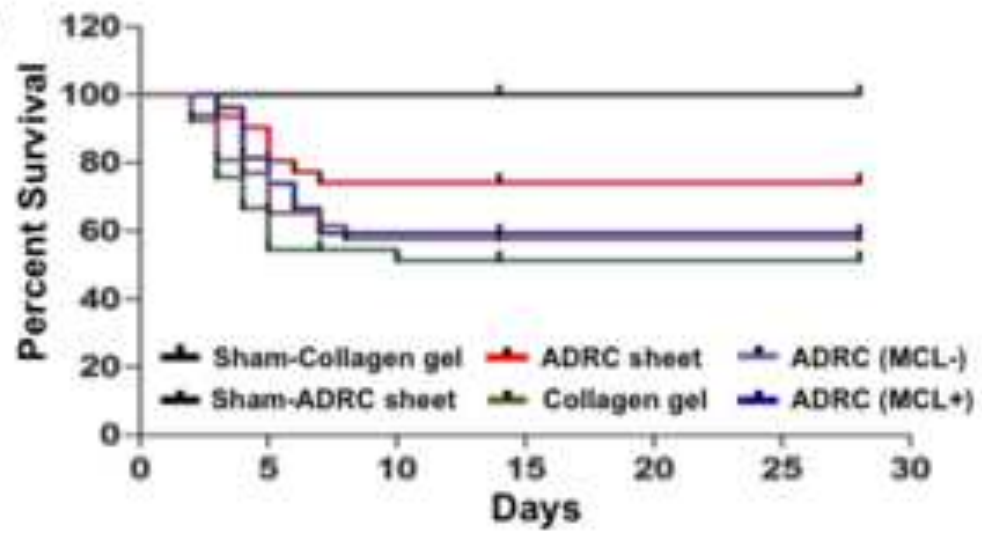

C
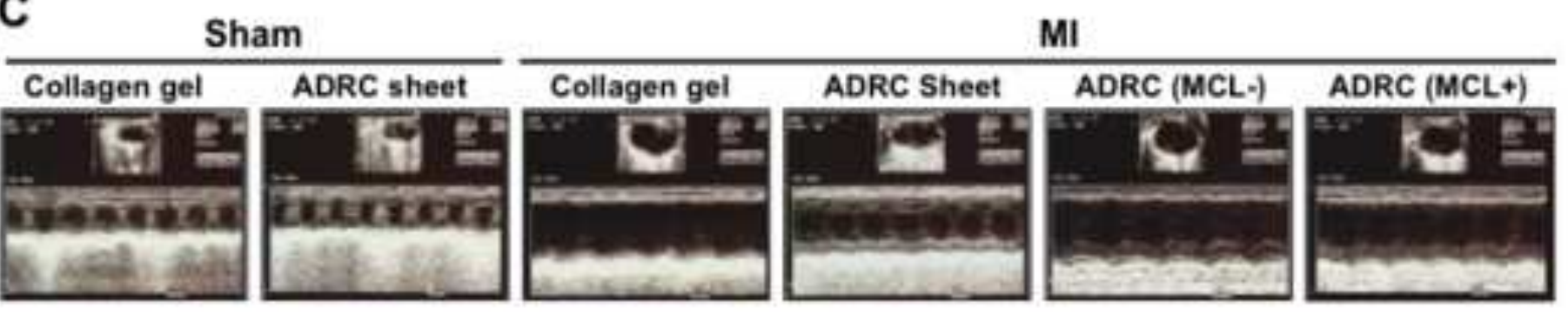

D

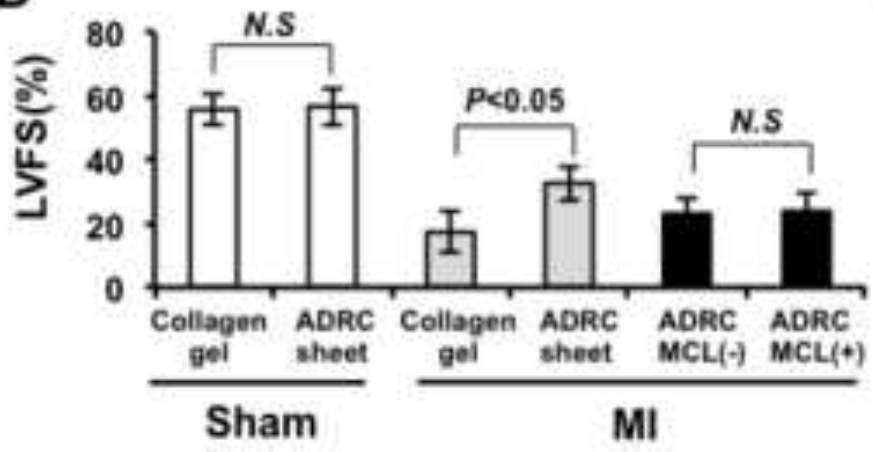

E

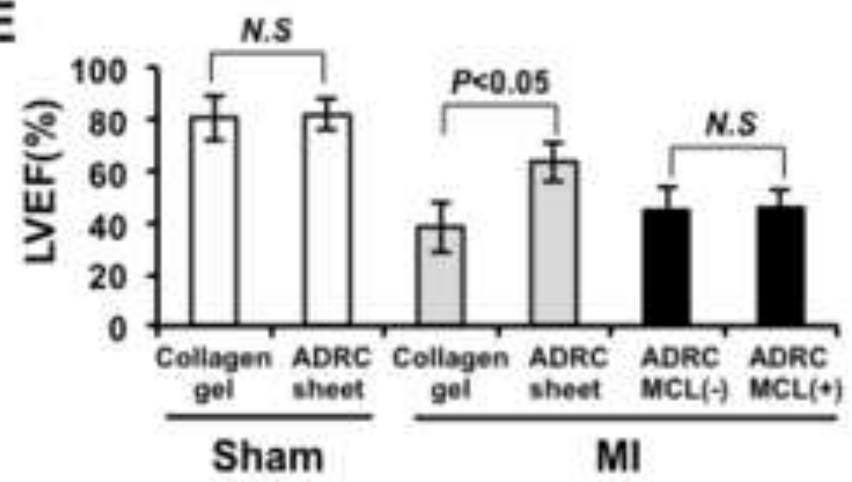

F Collagen gel ADRC sheet
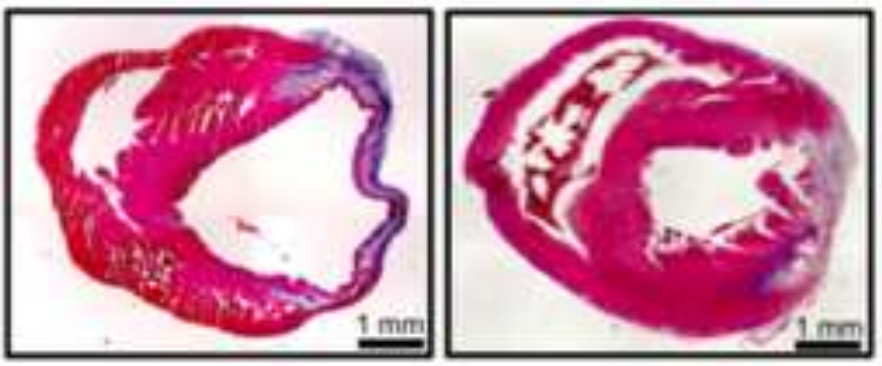

ADRC (MCL-)

$\operatorname{ADRC}(\mathrm{MCL}+)$
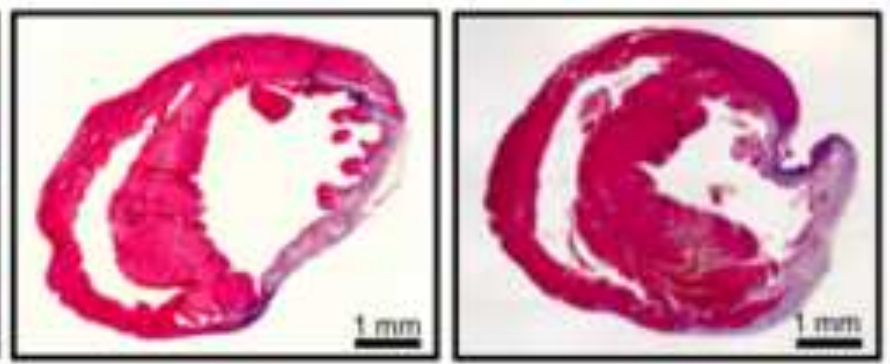

G

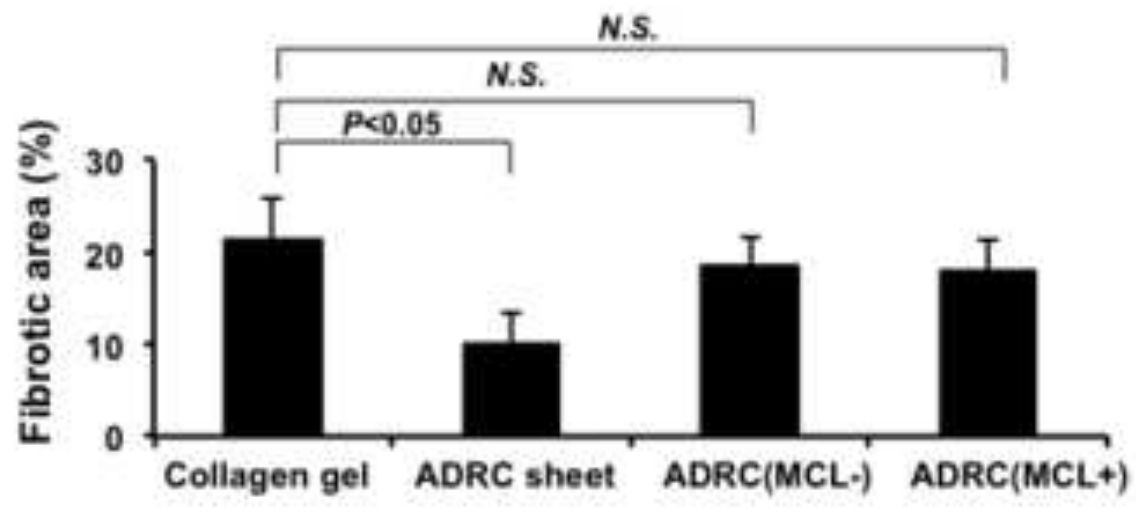

Figure 3 
A

Sham

Peri infarct area

Remote area

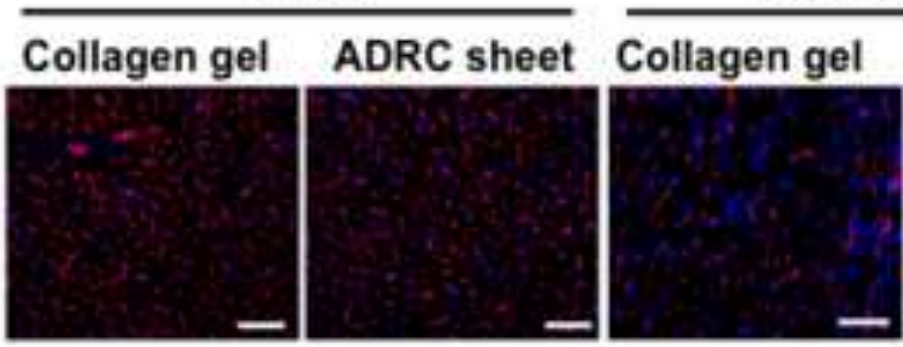

ADRC sheet
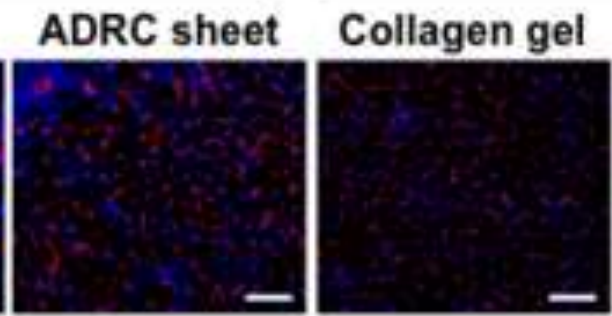

ADRC sheet

N.S.

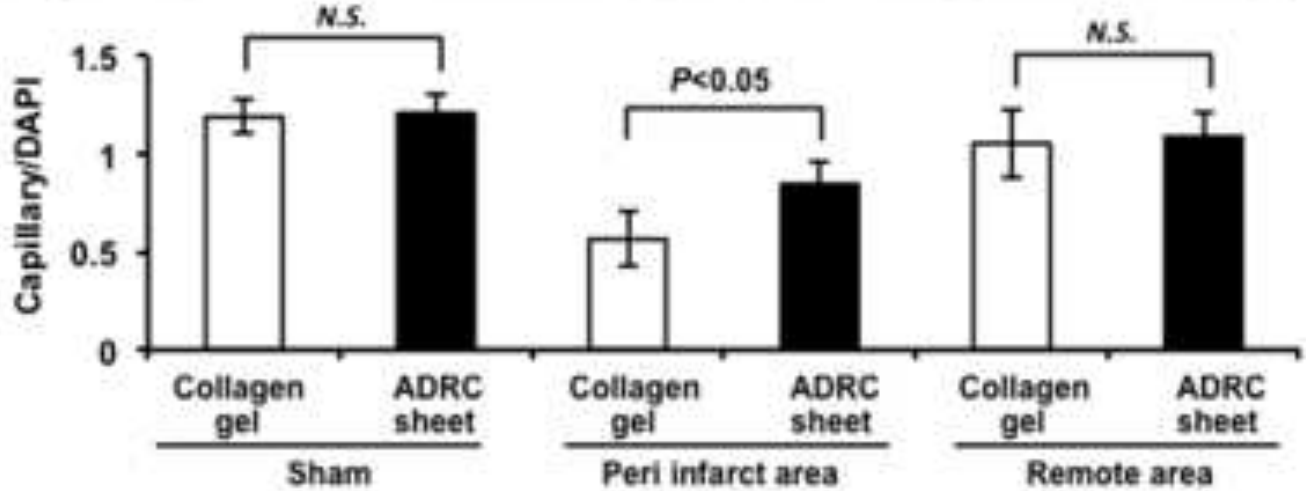

B

Sham

Peri infarct area

Remote area

Collagen gel ADRC sheet Collagen gel ADRC sheet Collagen gel ADRC sheet

TUNEL
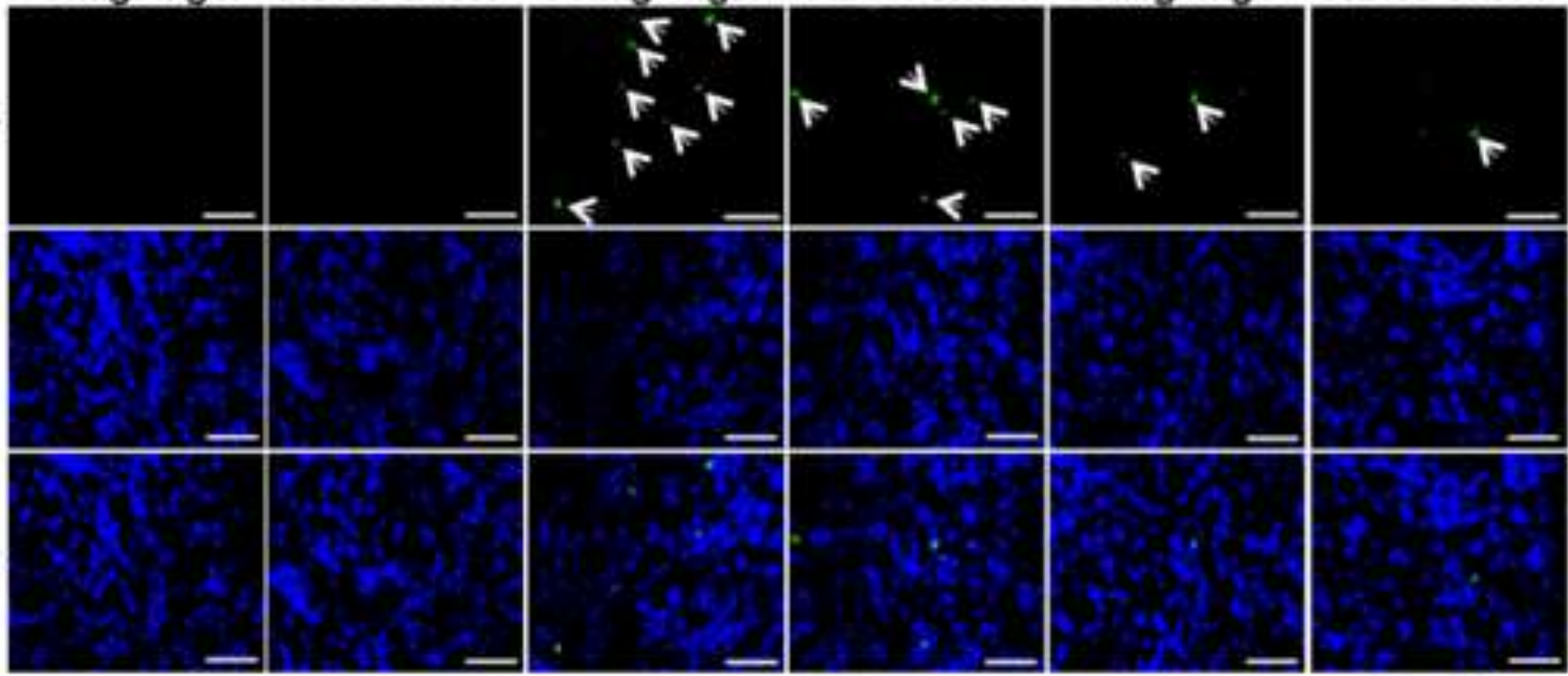

DAPI

Merge

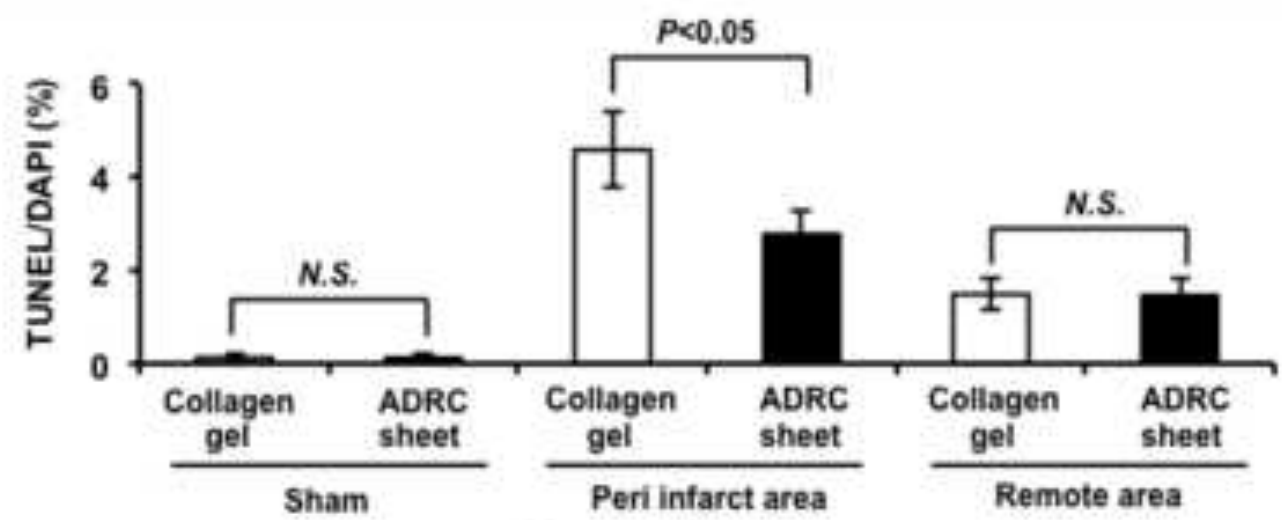

Bar: $50 \mu \mathrm{m}$

Figure 4 
A

VEGF

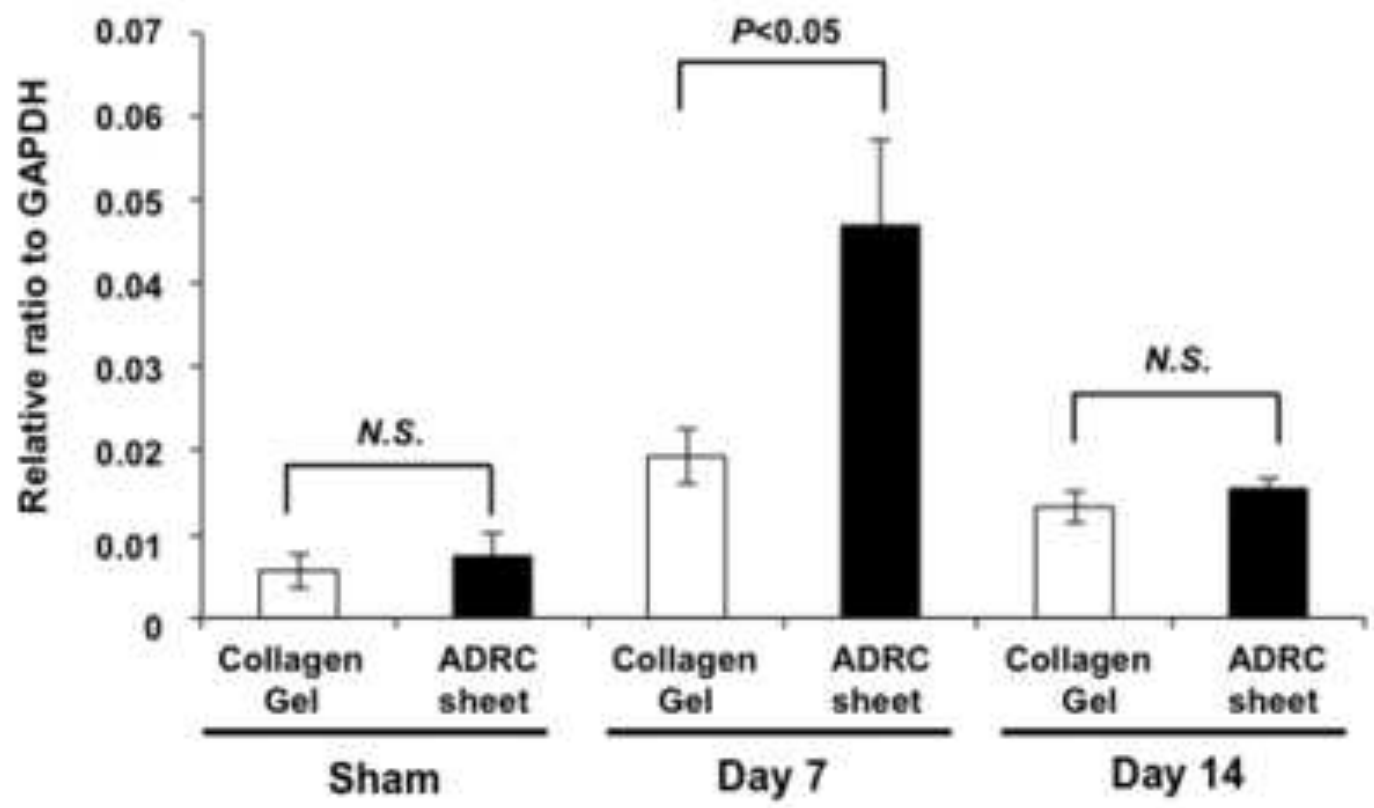

B

bFGF

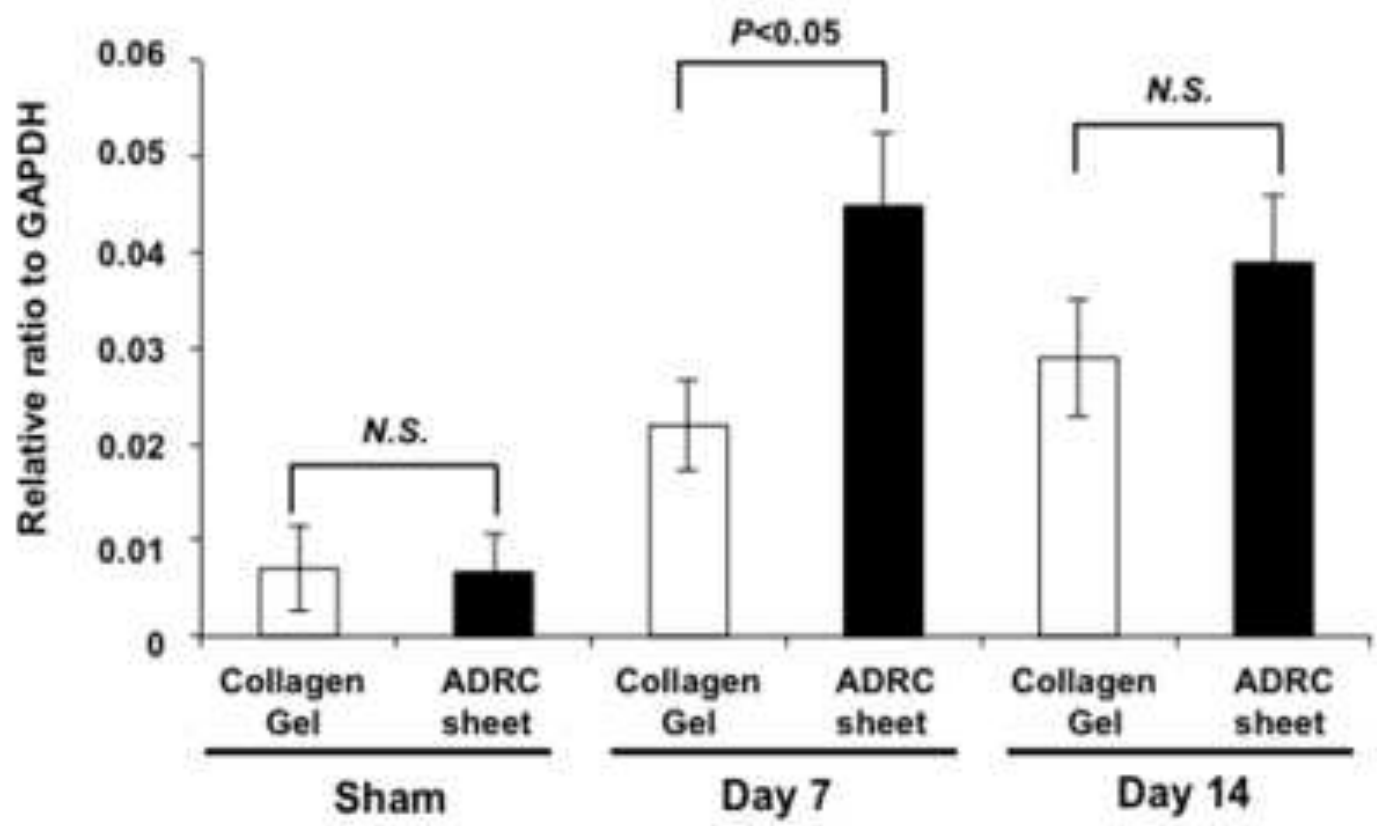

Figure 5 
A

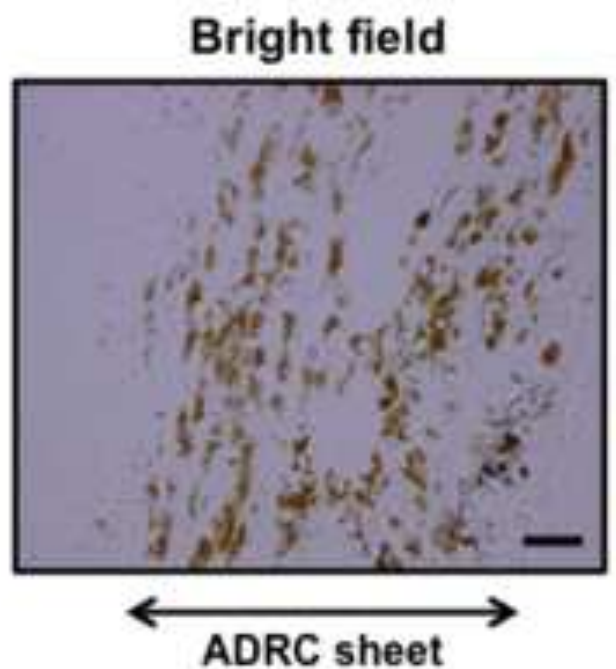

Fluorescent

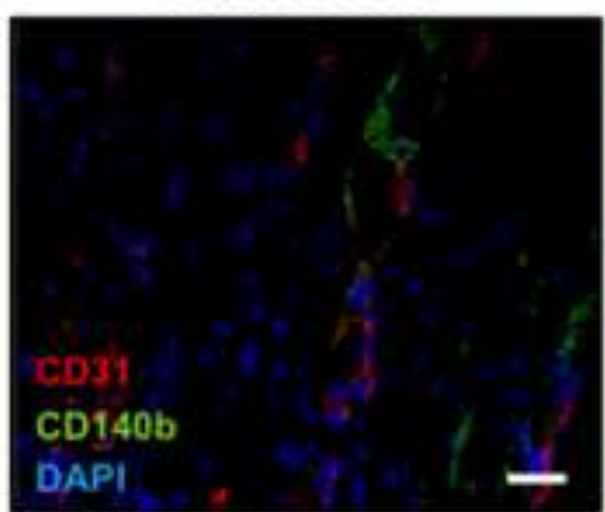

B

Bright field

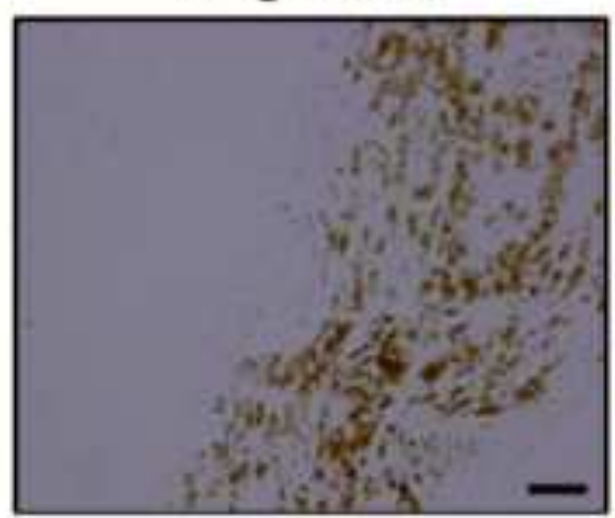

$\leftarrow$ ADRC sheet
Fluorescent

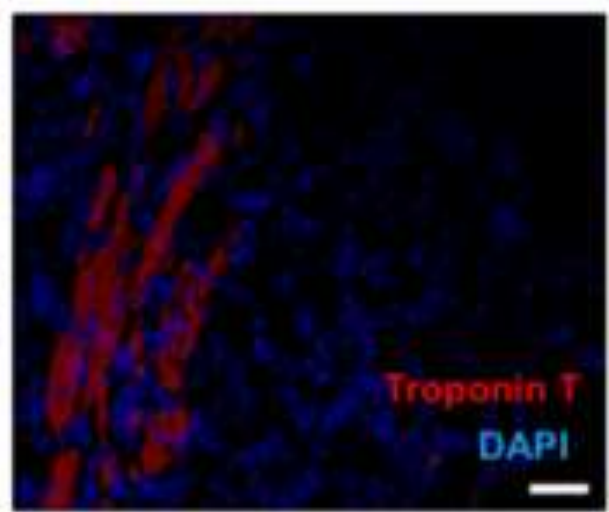

DAp
Merged

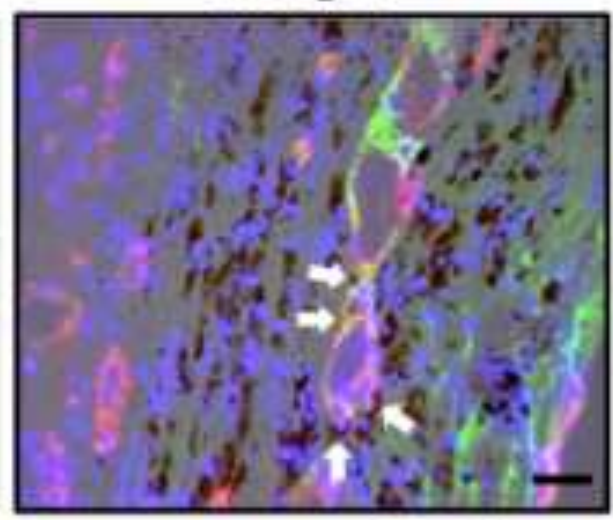

Bar: $50 \mu \mathrm{m}$
Merged

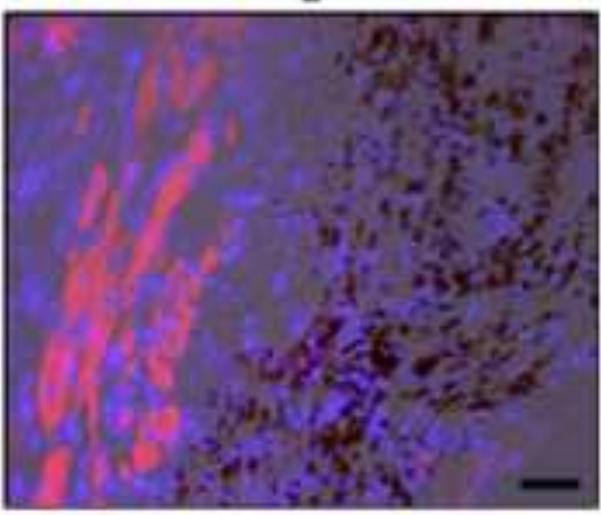

Bar: $50 \mu \mathrm{m}$ 